\title{
PRE-DECISION CONTROL PROCEDURES AS A CONDITION FOR ACHIEVING THE PURPOSE OF INVESTMENT
}

\author{
Łukasz DWOJAK \\ Higher School of Banking, Poznań, Faculty in Chorzów; lukasz.dwojak@chorzow.wsb.pl, \\ ORCID: 0000-0002-9851-2922
}

\begin{abstract}
Research background: Existence and development of companies strongly depend on their investments spending including capex expenditures. Regardless of scale of expenses an investment project should be analysed with regard to the risks involved, calculation of amount to be spent and probability of achieving expected effects. To realize this objective in a smooth and effective way a company should possess and use in practice procedures for analysis of investments projects - pre-decision control procedures.
\end{abstract}

Purpose of the article: The aim of the presented paper is to show the advantages of possession by companies the procedures for analysis of investment projects and necessity for their usage in case of preparing a new investment. Even the simplest procedure enables to define potential risks which can occur in time. In addition, such a procedure allows to analyse technical, financial and personnel issues related to introducing a new technology and purchasing machinery equipment.

Methods: The research method applied for preparing this article has been based on a survey addressed to business owners, financial managers and other persons involved in the process of analysis and acceptance of investment decisions in business units. The paper presents results of empirical research carried out by companies, mainly from Silesia region. The theoretical part is based on literature analyses.

Findings \& Value added: The empirical research did not confirm that companies using predecision control procedures for investment projects achieve their business and financial objectives more often than companies which do not have such procedures.

Keywords: Financial economics, corporate finance, microeconomics, industrial organizations.

\section{Introduction}

Every company which wants to survive on the market and strengthen its market position has to plan and carry out some investments. There are many kinds of company's investments for example purchasing shares of another company, spending money on capex purchases 
(for different types of assets), developing staff skills, R\&D activities etc. The faster a company wants to develop the more money for investments it has to spend.

The investment decisions play a key role in shaping future directions of company's development. That is why these decisions should always be a part of realisation of its strategy. An investment strategy, as a part of overall development strategy of a company, should be based on information and predictions concerning future macro and micro economic conditions, including main competitors. Another aspect of preparing an investment strategy is a current situation of a company, including financial standing, ability to obtain outside financing (bank's credit or issuing corporate bonds), the quality of its products and access to innovations in a particular sector of economy.

The capital expenditure decisions have short-term and long-term effects on financial standing of a company, because these decisions always concern money. In the time of realisation of an investment project all necessary expenditures are a financial burden for its cash-flow. When an investment is successfully completed it can increase profitability and ROE ratios.

Realisation of every investment project is always connected with different types of risks, for example:

1. financial risk - not achieving the business goals of investment,

2. liquidity risk - increasing cost of the project can negatively affect a cash-flow of a company,

3. technological risk - when new machinery, equipment or technology cannot achieve the planned volumes of production,

4. personnel risk - when a company cannot hire qualified workers for servicing new equipment.

In the case of realization of an investment project, the scale of economic risk is higher than in the case of business usual activities. The assumptions of an investment project relay on some predictions - company's managers try to predict future conditions for economic activities, which are unknown.

The main purpose of the article is to check if companies which prepare investment projects with the usage of pre-decision control procedures (in which they analyse the conditions of economic activity in the future as well as different types of risk involved) can achieve their business objectives more often than the companies which do not implement pre-decision control procedures for analysis of investment projects.

There are many different versions of pre-decision control procedures which are used by companies in practice. These types vary and depend on the sector of economy, the size of a company, possessed experience in the field and, last but not least, the amounts spent on the investment projects. In reality in the analysed aspect of companies' activities the most important difference between companies is whether they use pre-decision control procedures, or not. 
The article is based on empirical evidence coming from research conducted with the use of an Internet questionnaire. The survey was conducted on the group of 23 Polish companies in the first quarter of 2019 (mainly SME according to EU definition).

The author found this survey method to be the most appropriate to examine the way of realising investment projects by Polish companies, because of its convenience for participants.

A four-page questionnaire was used to gather data. The participants completed the questionnaire by means of the Internet tool enabling on-line answers to the questions.

The questionnaire had three main sections: (1) background questions about the company, (2) information about the number and scale of realised investment projects within the last three years and sources of their financing, (3) information about achieving goals of investment projects, degree of their realisation and changes in pre-decision control procedures or lack of them.

This paper is structured as follows: Section Two presents the relevant literature and Section Three discusses research methodology. In Section Four, the data collections and analysis measures are explained together with empirical results which are presented. Finally, discussions are presented in Section Five and conclusions in Section Six

\section{Literature review}

Achieving goals of investment projects greatly affects the extent to which a company can realize its strategy. For capital investments, management controls can be divided into two main groups: pre-decision controls and post-decision controls. Pre-decision controls include control mechanisms used before the investment decision takes place (Alkaraan and Northcott, 2007).

Some authors split pre-decision control procedures into strategic (having 'strategic' focus) and non-strategic investment projects ('operational' in nature). Typical examples of 'strategic projects' include company acquisitions and mergers, building new plants abroad and introduction of new technology of production (Accola, 1994; Van Cauwenbergh et al., 1996; Slagmulder, 1997). To prepare for a smooth realization of an investment projects companies can use different types of pre-decision control procedures before final decisions are made.

Conventional investment analysis techniques have been well investigated (see, for example Pike, 1996; Abdel-Kadar and Dugdale, 1998; Arnold and Hatzopoulos, 2000). Pike (1996) and Abdel-Kader and Dugdale (1998) found out that most companies use more than one financial analysis technique in investment appraisal. Arnold and Hatzopoulos (2000) found out that companies that are using in practice pre-decision control procedures placed the greatest emphasis on the discounting techniques (IRR and NPV) with NPV rated higher than IRR. 
Some researchers (i.e. Carr et al., 1994; Van Cauwenbergh et al., 1996) have pointed out that formal financial and risk analysis techniques in fact have remarkably little impact on strategic investment decisions.

The formal standard operating procedures for a company's capital investments usually define procedures to be followed in the planning, evaluation and selection phases, including the capital budgeting techniques to be applied (i.e., Alkaraan and Northcott, 2007; Arnold and Hatzopoulos, 2000).

The largest strategic capital investments require an approval from the Board of Directors (Melgin, 2016). The requirements for top management involvement and managers' interaction with other managers to coordinate investments can be formalized (i.e. Emmanuel et. Al., 2010; Jorgensen and Messner, 2010).

Verbeeten (2006) found that manufacturing companies use sophisticated risk analysis tools (i.e. simulation analysis and CAPM analysis) less frequently than other industries do. Instead, they use more frequently "naïve" practices, such as sensitivity analysis, scenario analysis, and adaptation of the required rate of return.

In the times of financial crises companies increased their emphasis on at least one control mechanism within a pre-decision control procedure (Huikku et al., 2018). Specifically, changing the tightness of controls and locus of decision-making were common in majority of companies. To a minor extent, companies also changed the degree of formalization, whereas none of the companies introduced a totally new control mechanism.

Alkaraan and Northcott (2006) pointed out that in regard to the use of risk analysis techniques, some of the relatively simple methods are used more often for strategic projects. This seems to suggest that strategic projects are perceived as requiring greater attention to risk issues, although there is little evidence that more sophisticated techniques supplant simple methods of strategic projects risk analysis.

\section{Research methodology}

The empirical evidence for the study was gathered by internet tool enabling on-line answers to the questions included in the questionnaire prepared for realization of the research. The research was done in the $1^{\text {st }}$ quarter of 2019. The author found this survey method to be the most appropriate, because business owners, as persons responsible for taking decisions concerning investment in the analysed group of companies, may complete it at any convenient moment.

In 2018 the net sales of the largest company whose owner participated in the survey exceeded 50 million EUR. This means that only this one company could be included in the group of large companies (corporations). The rest -22 companies are SMEs according to 
official EU definition ${ }^{1}$. In that group 12 companies are micro companies (net sales up to 2 million EUR) and 10 are small companies (net sales up to 10 million EUR).

Foreign investors possess more than $50 \%$ of capital in three companies $(13 \%$ of the analysed group of companies), in one company less than $50 \%$ ( $4.3 \%$ of the analysed group of companies), and the rest of the companies have only Polish owners ( $82.7 \%$ of the analysed group).

From the whole analysed group of companies, four are production companies $(17.4 \%)$, five - trade companies $(21.7 \%)$, and the remaining fourteen are service companies $(60.9 \%)$.

Only one company has operated on the market for less than 3 years $(4.3 \%)$, four have been on the market between 4 and 10 years (17.4\%), and the rest - eighteen companies - have been operating for more than 10 years on the market (78.3\%).

A group of eleven companies export their products (47.8\%) and the rest - twelve companies - do not sell their products abroad (52.2\%).

The internet survey method was chosen because it enabled easy access for completing the questionnaire at the most convenient time for the participants.

The questionnaire contained three parts: (1) information about a company including its duration, share of foreign capital within own capital, type of activity which it runs, number of employees and some basic financial data as of the end of 2018 including sales values, total amount of assets and information if a company exports its products; (2) information about investments made by a company in the period between 2016 and 2018, including the scope of investment projects and goal/goals which the company wanted to achieve by realizing these investments projects; (3) information of possessing pre-decision control procedures; information whether the expected return on the investment was assumed; whether the expected results were verified; what was the source of money which financed the investment project; what criteria were taken into consideration within the process of taking investment decision; what was the scope of pre-decision control procedures - did it cover all kinds of aspects of the investment project - financial, technical, personnel, risks involved, or maybe some changes were necessary within a pre-decision control procedures, resulting from experience of a company from the investment project; when were the goals of the investment not achieved, were any other actions taken; in case a company did not have any pre-decision control procedures before realising the investment and the goals of the investment project were not achieved, was a decision taken to introduce a pre-decision control procedure; what was the final amount spent on the investment project - what additional amount of money was needed for completing the investment.

Although in majority of questions the respondent could choose a few variants of the answer, in some cases the author used an open question formula enabling the respondent to give more precise and detailed information concerning a particular question. For example, in the case of

\footnotetext{
${ }^{1}$ According to Appendix no 1 to EU Commission Decree no 651/2014 as of 17 June 2014.
} 
question concerning introducing changes in pre-decision control procedures - what change/changes were implemented.

The data collected in the research are available on the website: http://inter102.ayz.pl/ ankieta_zestawienie.php.

The purpose of the article is to verify the following working hypothesis:

companies which possess pre-decision control procedures can achieve the goal/goals of their investment projects more often than companies which do not have such procedures.

\section{Results}

At the beginning of the second part of the questionnaire the companies were asked to declare if they realized any investment project within the last three years (2016-2018). The majority of firms, i.e. 19, informed that they carried out investment projects within the analysed period of time $(82.6 \%)$. The total number of investment projects was 59 , because some of the companies carried out a few projects within the analysed period.

The most frequent investment project was a purchase a fixed asset (for example: machinery, equipment, new technology lines etc.) - ten companies declared carrying out this kind of investment project $(43.5 \%)$. The detailed information concerning types of implemented investment projects is presented in Table 1 .

Table 1.

Types of investment projects implemented by companies

\begin{tabular}{|c|c|}
\hline Number of companies attending survey & 23 \\
\hline Companies which realized at least one investment project within the analysed period of 2016-2018 & 19 \\
\hline Total number of implemented investment projects by companies & 58 \\
\hline \multicolumn{2}{|l|}{ Types of implemented investments and number of projects: } \\
\hline $1 /$ modernization of already owned fixed assets & 5 \\
\hline 2/ purchase of new fixed assets & 10 \\
\hline 3/ purchase of intangible assets & 8 \\
\hline 4/ buying IT equipment & 9 \\
\hline $5 /$ purchase of a business car or a lorry & 10 \\
\hline 6/ construction of a new production plant & 3 \\
\hline $7 /$ purchase of a real estate & 6 \\
\hline $8 /$ buying financial assets & 1 \\
\hline 9/ purchase of shares of another company & 0 \\
\hline $\begin{array}{l}\text { 10/ other types of investment projects including establishing a new firm, R\&D projects or introducing } \\
\text { a new production line }\end{array}$ & 7 \\
\hline
\end{tabular}

The crucial information from the perspective of the main goal of the realized survey were included in the group of questions concerning processes of preparing of investment projects and analytical tools used for doing this. 
The first question from this part of the survey verified if a company possesses pre-decision control procedures. According the answers given by respondents eleven companies use pre-decision control procedures (47.8\% of the whole analysed group). The rest of companies twelve, do not have or use pre-decision control procedures. This means that from the group of nineteen companies which realised different kinds of investment projects eight companies did not use any pre-decision control procedures for preparing their projects.

The issue was analysed more deeply by asking the question concerning defining the financial goal/goals of implemented investment projects. In the aspect of financial control procedures a similar number of companies i.e. fourteen companies informed that they defined their financial goals with regard to realised investment projects. The remaining companies which realised investments projects - i.e. five, did not set a financial goal/goals for their investment.

In the next question it was verified if companies checked whether their financial goals were achieved. Eleven companies answered that they verified the results of investment projects.

According to the information from the next question the main source of money for realisation of investment projects were net profit and depreciation.

From the group of companies possessing pre-decision control procedures eight declared that the procedure enabled complex analyses of the investment project (all aspect of this project).

A group of twelve companies informed that all their goals of investment projects were achieved, six declared that they realised theirs goals only partially and one company did not achieve its goal of investment project.

In the last group of questions concerning modifying the pre-decision control procedures six companies stated that their-pre-decision control procedures should be modified/improved.

Only two companies decided to take any actions because of the fact that they did not achieve their financial goals of realised investment projects. It was for example an analysis of the market and a research of needs of target customers.

But finally a group of five companies declared that in consequence of problems with achieving their goals of investment projects they implemented a pre-decision control procedure.

From the group of companies possessing pre-decision control procedures two informed in the last two questions that their planned amount of money for investment projects exceeded the planned value of investment in the first case by $20 \%$, and in the second case roughly by $30 \%$ of planned budget for investment project. In practice that means that pre-decision control procedures of these two companies should be modified. 


\section{Discussion}

The author did not manage to find any publication of Polish researchers concerning the main subject of this work i.e. pre-decision control procedures. The foreign publications mentioned in point two: Literature review, are mainly concentrated on big and very big corporations in terms of sales - the so-called multinationals.

The author decided to concentrate on the group of Polish small and medium enterprises (SME), because of their importance for generating GDP, number of jobs created and relatively small amount of money spent on investment projects in comparison to Polish corporate companies (Laszek; Trzeciakowski, 2018).

The number of companies which participated in the research was twenty three. Based on the given answers in the questionnaire it seems to be enough for drawing some conclusions.

One of the companies participating in the research because of its scale of revenues (roughly 50 million EUR) seems to be a big company according to EU definition. This company possesses pre-decision control procedures. The rest of analysed companies - twenty two belong to SMEs group according to EU definition. Only ten companies from this group implemented pre-decision control procedures for preparing/analysing investment projects.

This means that in practice as much as $45 \%$ SMEs from the analysed group use pre-control procedures for analysing the way of spending relatively big amounts of money for investment projects. In the author's opinion this is a positive information.

But a greater number of companies - in fact majority of them, i.e. 55\% from the analysed group did not possess pre-decision control procedures. In that group of companies eight realised investment projects within the analysed period. Because of the fact that every company realised on average tree investment projects (nineteen companies implemented fifty nine projects) roughly twenty four projects were realised without any financial or risk assessment.

Even a simple analysis concerning possible impact on a company's cash-flow and different kinds of risks involved in an investment project could be a basis for making a decision for spending money decisive for the future of a company. The other part of the analysis should verify if the investment project fits a current development strategy of a firm.

The main aspect of the article - verifying a working hypothesis that companies which possess pre-decision control procedures can achieve the goals of their investment projects more often than companies which do not have such procedures - based on the data from the research questionnaire is presented in Table 2 and Table 3. 


\section{Table 2.}

Results (answers) from the group of companies declaring possessing pre-decision control procedures

\begin{tabular}{|l|l|}
\hline Total number of companies declaring possessing pre-decision control procedures & 11 \\
\hline Number of companies informing about achieving the goal/goals of their investment projects & 7 \\
\hline $\begin{array}{l}\text { Number of companies informing about partial achievement of the goal/goals of their investment } \\
\text { projects }\end{array}$ & 4 \\
\hline
\end{tabular}

\section{Table 3.}

Results (answers) from the group of companies declaring not possessing pre-decision control procedures

\begin{tabular}{|l|l|}
\hline Total number of companies declaring not possessing pre-decision control procedures & 8 \\
\hline $\begin{array}{l}\text { Number of companies informing about achieving the goal/goals of their investment projects despite } \\
\text { lack of pre-decision control procedures }\end{array}$ & 6 \\
\hline $\begin{array}{l}\text { Number of companies informing about partial achievement of the goal/goals of their investment } \\
\text { projects despite lack of pre-decision control procedures }\end{array}$ & 2 \\
\hline
\end{tabular}

Two companies did not answer this question and another two informed about lack of realizing any investment project, which in general gives four companies not involved in any investment project within the analysed period, as it was mentioned earlier.

Based on the data available from the research the author has to state that the assumed working hypothesis was verified negatively.

$75 \%$ of companies (i.e. six companies) which did not possess pre-decision control procedures fully realised their goal/goals of investment projects. $25 \%$ of companies (i.e. two companies) partially realised their goal/goals of investment projects.

On the other hand from the group of firms which declared possessing pre-decision control procedures only $63 \%$ (i.e. seven companies) fully realised their goal/goals of investment projects. $37 \%$ companies (i.e. four companies) partially realised their goal/goals of investment projects.

\section{Conclusions}

The research has shown that relatively big number of Polish SMEs do not use any kind of pre-control procedures for preparing an investment decision process.

Despite negative verification of the working hypothesis assumed in this work it could be said that majority of companies which made investment projects within the analysed period possessed pre-decision control procedures (i.e. 57.8\%), with regard to the whole researched group it was $47.8 \%$.

However, in the author's opinion the picture of the way of preparing and realizing investment projects by SMEs is still unclear. We do not know why firms did not use at all any pre-decision control procedures. And how it is possible that despite that fact a big group of 
companies still can achieve the goals of their investment projects, even more often than the group of firms possessing pre-decision controls procedures.

In the opinion of the author the research should be continued but with a larger number of participating companies. The questionnaire used in the next research could be further developed as well and contain additional questions. These questions should concern for example an investment project approval in the companies without pre-decision control procedures - how it is realised in practice without any internal procedures.

Another question could explore the issue of size/scale of investment projects - how the amount of money spent on investment projects influences the fact of usage or lack of usage of any pre-decision control procedures.

Probably in practice in the case of investment of relatively small scale (in terms of money spent) the majority of SMEs do not introduce any pre-decision control procedures when they just buy another business car or a truck - this hypothesis could be verified as well.

And finally - partially achieved goal/goals means that another step must be taken to make up for lack of expected results. What the companies' reactions in these situations are and how they are going to complete their investment projects - that's another interesting issue for analysis.

\section{References}

1. Abdel-Kader, M.G., and Dugdale, D. (1998). Investment in advanced manufacturing technology: A study of practice in large UK companies. Management Accounting Research, 9(3), 261-284.

2. Accola, W.L. (1994). Assessing risk and uncertainty in new technology investments. Accounting Horizons, 8, 19-35.

3. Alkaraan, F., and Northcott, D. (2007). Strategic investment decision making: The influence of pre-decision control mechanisms. Qualitative Research in Accounting and Management, 4(2), 130-150.

4. Alkaraan, F., Northcott, D. (2006). Strategic capital investment decision-making: A role for emergent analysis tools? A study of practice in large UK manufacturing companies. The British Accounting Review, 38, 149-173.

5. Arnold, G.C., and Hatzopoulos P.D. (2000). The theory-practice gap in capital budgeting: Evidence from the United Kingdom. Journal of Business Finance and Accounting, 25(5/6), 603-626.

6. Carr, C., Tomkins, C., Bayliss, B. (1994). Strategic Investment Decisions: A Comparison of UK and German Practices in the Motor Components Industry, Avebury, Aldershot. 
7. Emmanuel, C., Harris, E., and Komakech, S. (2010). Towards better understanding of capital investment decisions. Journal of Accounting and Organizational Change, 6(4), 477-504.

8. Huikku, J., Karjalainen, J., Seppala, T. (2018). The dynamism of pre-decision controls in the appraisal of strategic investments. The British Accounting Review, 50, 516-538.

9. Jorgensen, B., and Messner, M. (2010). Accounting and strategizing: A case study from new product development. Accounting, Organizations and Society, 35, 184-204.

10. Laszek A., Trzeciakowski R. (2018) Report: Perspectives for Poland. Investments versus economic growth. Warsaw: Foundation of Civil Development.

11. Melgin, J. (2016). Representation, materiality and decision control; essays on the role of board of directors as an intermediate actor in corporate Governance. Doctoral dissertation. Helsinki: Unigrafia: Aalto University.

12. Pike, R. (1996). A longitudinal survey on capital budgeting practices. Journal of Business Finance and Accounting, 23(1), 79-92.

13. Slagmulder, R. (1997). Using management control systems to achive alignment between strategic investments decisions and strategy. Management Accounting Research, 8, 103-139.

14. Van Cauwenbergh, A., Durinck, E., Martens, R., Laveren, E., and Bogaert, I. (1996). On the role and function of formal analysis in strategic investment decision processes: Results from an empirical study in Belgium. Management Accounting Research, 7, 169-184. 